\title{
Use of Force Account Procurement Method for Development of Small and Medium Contracting Firms in Mbeya, Tanzania
}

\author{
Kaula Stephen \\ P.O.BOX 516, Mbeya \\ kaula_stephen@yahoo.com
}

\begin{abstract}
The study investigates on the value of using force account procurement method in development of small and medium contracting firms. To explicitly reveal what is behind the scene three objectives were formulated which were:-to examine the features of force account in procurement undertakings; to determine the value behind force account procurement method in procurement process towards development of SME and; to assess the bottleneck over effective enforcement of force account policy. The target population being (30) contractors, engineers and technicians employed with TANROADs, TARURA, TANESCO, and REA and those self-employed (37) in Mbeya. Snow ball sampling technique was used to obtain a total of 67 respondents deduced. The semi-structured intereview and checklists schedules being used to gather the facts then descriptively and through the use of simple frequencies and percentage the reality was revealed:- force accounts involves local contractors by $100 \%$ executing contracts defined under force account policy to its end. Moreover force account is $100 \%$ local community participation procurement regularities; force account increases competence (70\%); experience $(66 \%)$ and financial capacitating (59\%) of local contractors. Furthermore it was revealed that though projects assigned under force account are to be executed by indigenous contractors by $100 \%$ but from the field area it was found only $50 \%$ to be sustained. This gap of $>50 \%$ of contracts under force account none executed was revealed to be caused by technical deficiency given the wilks' lambda, $\lambda<0.9$; management incompetence given ${ }^{\top} \mathrm{X}<5.0$ and $\delta^{2}>0.05$; cases over (unethical practices reported $>60 \%$; financial difficulties $>54.7 \%$; and tax burden $>60 \%$ ).
\end{abstract}

Keywords: Force Account, Procurement Method, Small and Medium contracting firms, Tanzania

\section{How to Cite:}

Stephen, K. (2021). Use of force account procurement method for development of small and medium contracting firms in Mbeya, Tanzania. International Journal of Finance Research. 2(2). 94-110. DOI. https://doi.org/10.47747/ijfr.v2i2.311. 


\section{Introduction}

Preferential treatment for the purpose of developing small and medium contracting firms has been a current agenda to most of governments in the World especially in developing countries( Schapper \&Gilbert,2006).Implementation and use of preferential treatment government of host countries has found to be used in developing local experts (BMAU,2015). Preferential treatment said involves providing a great chance to local contracting firms to win and execute procurement contracts. The opportunities or works to be assigned might be those which involve constructions such as civil engineering, bridges and road renovation and demolition. Indeed the preferential treatment is paid over consultancy services such as teaching; medical treatment care; non-consultancy services such as environmental cleanliness as well as supply of goods. This then help to develop the indigenous contractors technically and managerial wise to execute the contract to the end successfully.

According to Ofori (2000), the strategies of developing local contractors have been the initiative of the government of Indonesia has been undertaking. This is from the fact that by developing indigenous experts is like making own product/service. One of the advantage revealed from this study is that in-sourcing is cheaper than out-sourcing. The same making own experts help to meet on time delivery of the service because of the availability of those internal experts in place and any time when needed. Contextually the study by Ofori (2000) stipulated one of the attribute/variable the study under discussion has jotted down i.e. contribution/value of effective implementation of force account policy. The value that have added by the study underhand is to include other variables such that of factors which lead the force account policy in Tanzania being not implemented to its $100 \%$ but $<50 \%$ level reached.

In the country of Uganda with reference to what was said by UNABCEC (2014) the enforcement of public private partnership as one of the strategy towards developing local contractors for them full participate in execution of procurement undertakings. Indeed for development of rural infrastructures. The study underhand has been innovative by pinpointing more other strategies /methods and policies apart from force account. Other methods/policies revealed by this study under discussion that increases the engagement or participation of local contractors both for procurement works advertised locally (such as those defined under force account) and internationally ones are Build and design, Build Operate Own Transfer, Collaborative procurement and turnkey contract. Apart from empowering local contractors for them compete fairly for international advertized tenders such that through use of International competitive tendering but those methods found to develop local contractors financially, technically and managerially as force account revealed to foster.

The enforcement of force account policy in Tanzania came in following a procurement reforms over the PPA 2004 to PPA 2011 and regulations of 2013.This indeed came following the gap revealed over majority of indigenous contractors to lose most of works procurement opportunities by $>60 \%$ because of global stiff competition and international harmonization in construction industries. Following a globalization and liberal markets in procurement which allow the contractors from other Worldwide to apply for the tender opportunities come on hand or seen from tender portals/websites/internet sources then competition has became stiff. This is 
then is a reason why most of procurement of works opportunities are won by foreign contractors and therefore leaving the indigenous Tanzanians underdeveloped (non-experienced) because of not being engaged in executing complex and high valued projects.

The force account policy as the government of Tanzania aimed at over developing SMEs has less been attained following the challenges facing it. Despite of the Tanzanian government speculating openly that the REA projects are to be executed by local experts but these opportunities have not been much spreaded to most of local contracting firms in which only $45 \%$ of these projects are executed. Moreover despite of $100 \%$ declaration that TARURA projects are to be run by local contractors but to find that only $55 \%$ is fostered.

The $50 \%$ in average over procurement opportunities executed by local contractors under deployment of force account is not enough to say the policy has employed effectively towards development of small and medium contracting firms. Some of pitfalls revealed from the field why force account policy is not much extended in Tanzania were :-i) incompetence or technical and managerial incapability ii) ethical deficiency (most of local contractors were found not trustful, not faithful, lazy, they do corrupt and not honest) iii) financial difficulties iv) tax burden

This study was guided by the Contractor Performance Development Model (CDM). This model was found by Dlungwana \& Rwelamila (2015). This Model suggested that for a local contractor to be able to perform a contract to completion then technically and managerial wise should be capable. Thus developing a small and medium contractor should associate training, mentorship and performance assessment activities. Moreover for these attributes to be attained then partnering is to be emphasized. Furthermore development of local contractors should call for separate industrial entity with its distinctive strategies. Indeed the Model propose on the significance of undertaking research to reveal the actual need of the market to be in a position to deliver the service which is of the preference and meet the need of client or market.

Despite of the contribution made by CDM but some important issues were left which then have been addressed by the study underhand. Those issues accommodated under force account procurement strategy were financial capacitating and importance of executing/demonstrating codes of conduct in the whole project management cycle. These then are pre-requisites for a local contractor to be trusted and awarded a contract to perform even for those projects which are defined under the force account. By being given a chance to execute the contract is the strategy that help to develop local contractors technically, experienced wise and managerially.

\section{Research Method}

The study applied a mixed research approach though qualitative elements overspread the quantitative elements. Moreover the grounded theory research design was indempedeted. The study was carried out in Mbeya. Mbeya is one of the region the projects defined under force account such City and Rural roads infrastructures require to be executed by local experts by $100 \%$ but to observe it is only $<50 \%$ level of these works are executed. This then created a dilemma that forced a researcher to conduct a research in this specific area though the casual of the gap and what is to be done to fulfill this gap is to be used as model by other parts of Tanzania and World in general. Moreover the descriptive-survey research design was employed. The

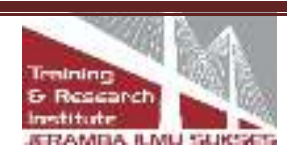


target population being (30) local contractors employed with TANROADs, TARURA, TANESCO and REA and (37) self employed to derive to 67 respondents the facts over the study under hand were revealed. By applying the confidence level of $90 \%$ and standard error of estimate $=0.1$ in deriving to 96 sample of respondents the formula $n=p q\left(Z \alpha /{ }_{2} / E\right)^{2}$ was employed, where $\mathrm{p}=$ probability value $=0.5, \mathrm{p}=1-\mathrm{p}, \mathrm{Z} \alpha / 2=$ normal probability distribution at a 2 -tail $=1.65$ and $\mathrm{E}=$ maximum/standard error estimate $=0.1$

The facts from 67 sample frame were obtained by using semi-structured interview, checklists as well as observation. Secondarily the reality about the study under hand was obtained by reading books, reviewing Journal articles and watching TV. The collected and edited data were analyzed descriptively by employing mean ( $\mathrm{X})$ and standard deviations $\left(\delta^{2}\right)$. Moreover the simple frequency distribution tables, bar and column graphs were used for presentations of the facts.

\section{Results \& Discussions}

\subsection{Contributions of Force account in development of Small and Medium contracting firms}

Force account policy came following reforms in public procurement Act 2004 to PPA 2011 section 59 which required use of local experts in executing some of procurement works defined under force account. This was purposely executed following the inventions over global harmonization in procurement undertakings which later led into stiff competition. These international platforms limited chances of local contractors fairly compete and win the procurement opportunities because of financially being incapable and more other perquisites happened not to be met (See Table 1 below). This discrepancy was also reported by Kaula (2017) in his study "why most of procurement opportunities in Tanzania are won by foreign contractors?" in which it was revealed that it is by $100 \%$ (of $5 \%$ ) equated to $>60 \%$ of these complex and risky projects are won by foreign contractors though by $95 \%$ these chances were left for local contractors with professional classes I - III .

Procurement reforms the government of Tanzania through the PPD and PPRA have been undertaking has helped local contractors getting chances of executing contracts defined under force account procurement method though not by hundred percent ( See figure 2 below). This is then the area of weakness this study has addressed to observe the projects under force account policy are executed $100 \%$ by local contractors.

The motives of force account policy though not sustained by hundred percent certain (little chances shown in figure 3 below over the level of force account executed entails). This was indeed proved that despite of small and medium contracting firms being aware of the procurement opportunities through different reliable sources as shown in figure 4 but the results shows that discrepancy still exist in executing the force account policy to $100 \%$.Either the facts over the motives of force account expected to be achieved were shown in Figure 1 below:- 
Figure 1: The roles of Force account in development of Small and Medium Contracting Firms

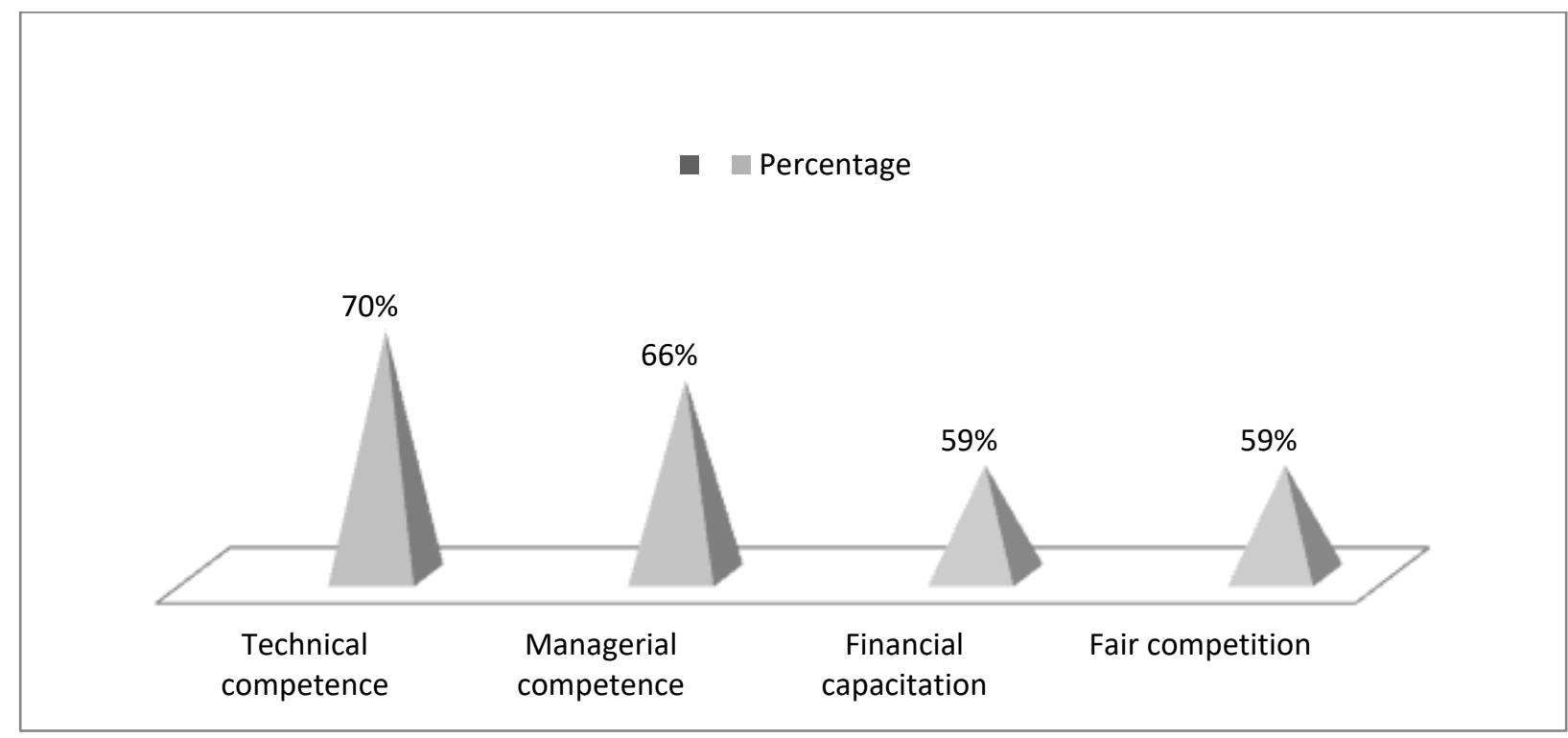

Source: Field data (2019)

The force account procurement policy found to equip small and medium contracting firms technically by $67 \%$, managerially (66\%), financial empowerment (59\%) and fair competition horizontal equity by $34 \%$. The fair competition also applies even if a contract is not under the category of force account say a National competitive tendering or/and international competitive tendering method. This fair competition was found to be influenced by financial capability small and medium contracting firms acquired what was also proposed by Nasser (2011) in the study "Improving Bidders Competitiveness Strategies in construction industry Projects". Actually this is the typical motive over the reforms and deployment of force account though these innovations have not yet been propounded following the revealed challenges as shown in (Tables 1, 2, 3; Figures 5, 6, 7 and 8).This discrepancy over insignificant level of value reached by implementing force account from the research area was moreover shown in Figure 2 below.

\subsection{The level of Value reached by implementing Force account}

Force account as it has stated above aimed at involving local procuring entities in procurement undertakings. Force account motivated at developing or making own experts which then discourage outsourcing for non-core activities to be executed. This came following the fact that making is cheaper than buying. It is by creating own experts of which reliability and accessibility of the service is there fostered any time when need follow due (Hernes,1988).In different procurement undertakings where procurement of works entails the level of development reached by small and medium contracting firms are those under construction of public infrastructures. More information from the field area was shown below in Figure 2 below:- 
Figure 2: Value reached by executing Force Account

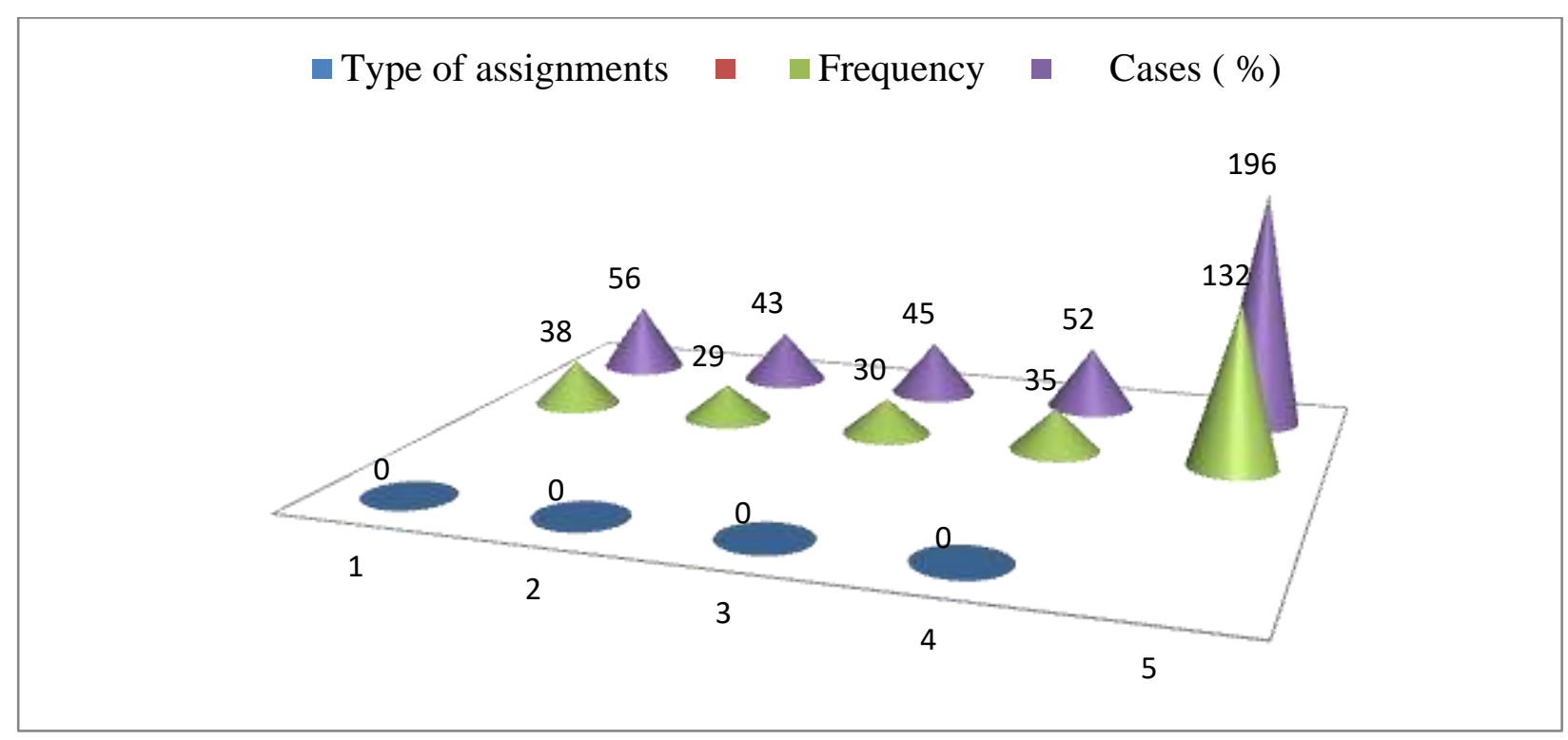

Source: Field data (2019)

The public infrastructures being health centers, schools, safe and sewerage infrastructures, electrical infrastructures the level of value attained by executing force account were case responses $=60 \%$; supply of goods cases $=43 \%$; executing consultancy services such as teaching $=52 \%$ and Non consultancy services such as sweeping, gardening and environmental cleanliness $=45 \%$ cases

This is then a message to the local contractors and policy makers that the force account is not full exhausted .This then gives a paved way of restructuring the system so that the value reaches $100 \%$.This is to say for efficient exhaustment (by hundred percent) of force account policy the SMEs need to act ethically and competently. Indeed there should be ways of empowering them financially and managerially such that over use of collaborative procurement and frequently running of structural training programs. The results in figure 4 above are contrarily from what was reported by Valdovinos \& Lorick (2013) on the importance of using in-house/local experts in execution of the procurement works. It is with this then it was revealed that using in-house experts is cost effective as compared to use of external persons in execution of procurement contracts.

\subsection{Awareness over procurement opportunities}

Information symmetric is vital aspect for someone become aware of the opportunity to execute in (Karriri,2011).From the research area information over the procurement opportunities executed under force account found to be not a problem. It was moreover revealed to be facilitated by stacking the tender opportunities on the Notice Board or offices of village, Ward Executive 
officials and Municipals $=41 \%$. This therefore indicate that information asymmetric was not a gap for local contractors apply for the chances, win and executes the projects defined under force account fully by hundred percent. Only to remind the small and medium contracting firms is that they should not be waiting for opportunities to be disclosed by procurement officials first but they should struggle seeking for those procurement opportunities on their own. Another reliable source of information over the procurement opportunities revealed from the field was the $32 \%$ for the Village/Ward Executive Directors and Councilors. More other sources of credible information found from the field were tender portal or websites of Ministries, TARURA, REA= $10 \%$; friends and peer $=8 \%$; social networks such as what sap, Jamii-forum $=8 \%$ and radio and other mass media $=1 \%$.These are the sources what these SM contracting firms have to use in searching information of their need what was revealed from the field. Sustainability over access to information pertaining procurement opportunities is contrarily from what was suggested by Kajwangya (2008) on reviewing the areas of improvement in procurement. In the other hand the study was significant to inform the stakeholders that technological inventions in tendering process such that over employment of e-procurement is a vital juncture to be adopted and applied.

\section{Figure 3: Awareness of procurement opportunities to be executed under Force account}

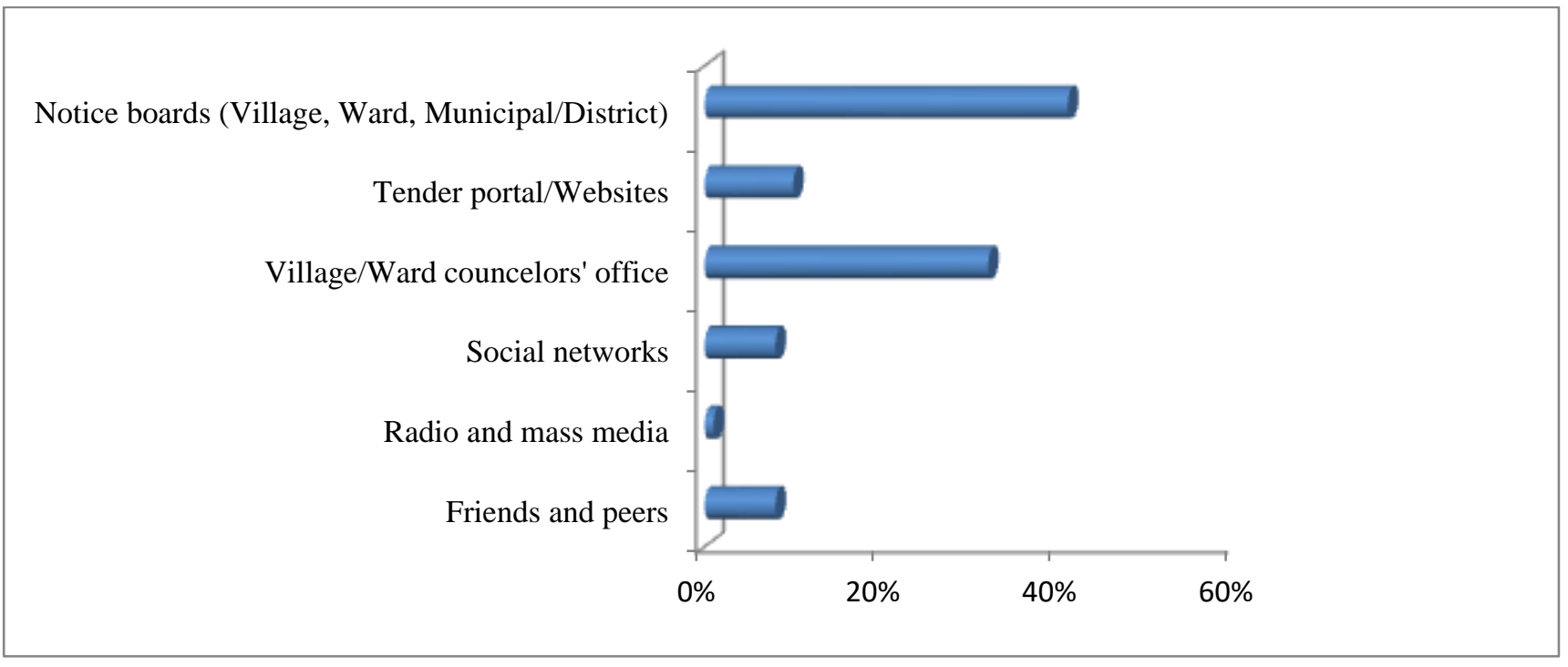

Source: Field data (2019)

\subsection{Wining rate of tenders under force account}

The winning rate of bids that are to be executed using force account procurement method is not impressing in balance of the extent to which these small and medium contracting firms are aware of the procurement opportunities to be executed under this policy. While it was revealed SMEs to be aware of the opportunities by $>80 \%$ ( as indeed shown above in subtitle 3.7) through different sources such as peers, friends, what sap platforms, radio, the TARURA, tender portal, 
websites, village /ward Executives Notice Board but the chance of winning the tenders defined under force account was found inadequate. It is was with the result of $<60 \%$ (with a response over good $=20 \%$; average $=56 \%$ ) as compared to response over worse not to mention $=24 \%$ what reveal the deficiency in executing the contracts under force account. Indeed this might be because of most of these SM contracting firms are not formalized for them to be awarded contract to execute but more other dilemma as it has stipulated above are the counting factors. Infact innovation has not been demonstrated to observe the force account is executed $100 \%$ by local contractors such as technicians from JKT ('Jeshi la Kujenga Taifa') in Tanzania.

It is from this study therefore it is recommended that to increase the chances of projects being executed by local experts through force account then the government/policy makers should think of initiating home contracting. This means that construction of individual private houses or factory buildings have to follow the same procedures of tendering as it is to other procurement assignments. This then should involve procurement and supplies professionals acting in between the supplier (contractor) and the client. This is from the facts the whole said $<60 \%$ of contracts executed under force account are the public ones and therefore by executing home contracting then the chances might rise to at least higher levels. Home contracting then has to go with formal way of operation in which every contract to be awarded a contractor to perform and even if a sub-contracting will be done then that contractors/sub $\mathrm{H}$ contractors should have registered by respective Boards i.e. CRB, ERB, AQRB and the business / construction firm being licensed and insured. Apart from increasing the chances of executing contracts such that of construction of schools, health centers, water sewerage systems, wiring but also home contracting will help to minimize or eradicate number of cases/ disputes over the project completed while lack the quality ingredients expected by the client or project owner.

\subsection{The level of Technical deficiency in executing Force Account Policy}

The quality of deliverables is determinant factor over whether the procurement and execution of the contract was performed in accordance to specifications. In the real World there is this concept i.e. Garbage in Garbage out which means that if the input has error do not expect the outcome or output to be good. Specifications are references or compatible technology an organization is running and thus a contractor should adhere to this as these are expectations /targets/standards put forward by the client or project owner. 
Figure 4: Wining rate of tenders over the procurement opportunities coming in to be executed under force account

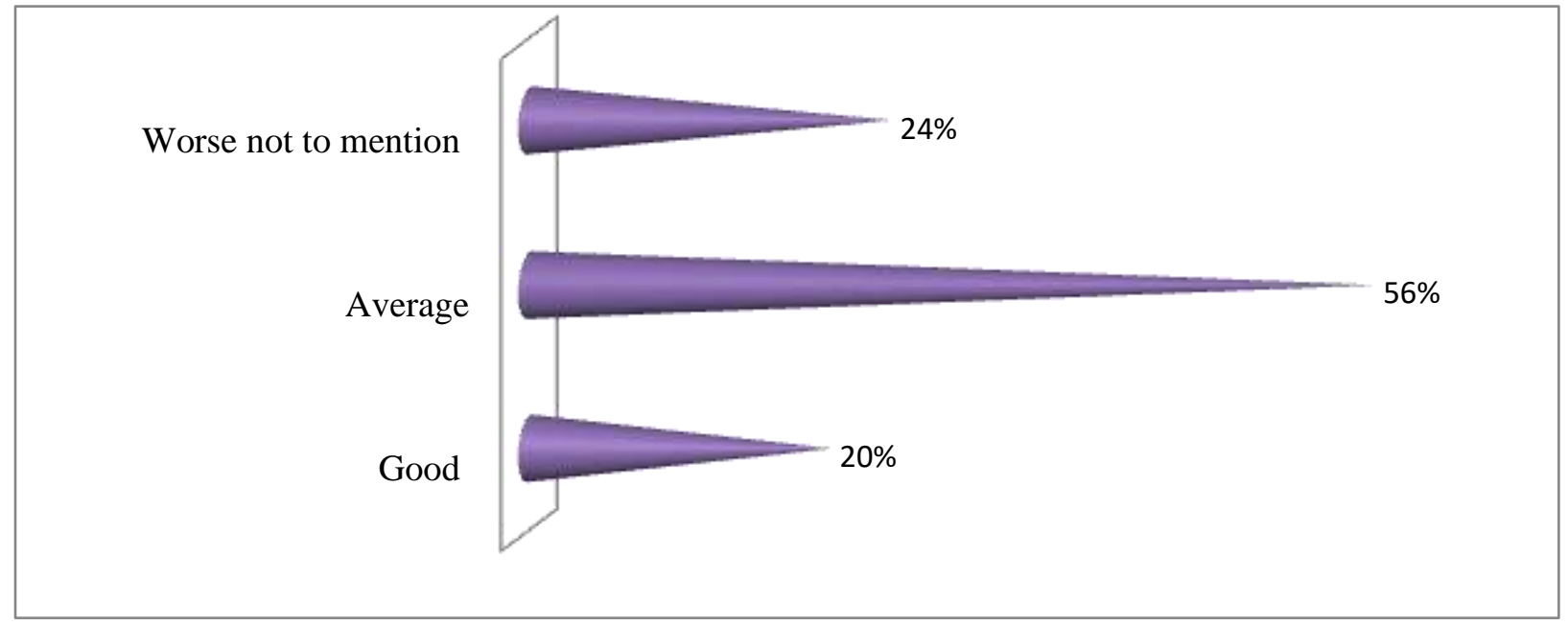

Source: Field data (2019)

Table 1: Technical deficiency in executing Force account

\begin{tabular}{|c|l|c|}
\hline S/N & Sub-constructs & Mean Wilks' Lambda \\
\hline 1 & Execution to according to specification & 0.67 \\
2 & Dimensions and other parameters are adhered & 0.57 \\
3 & Ability to use technology compatible to organization & 0.81 \\
4 & Blue prints are adhered & 0.74 \\
5 & The Bill Of Quantities (BOQ) execution & 0.84 \\
6 & Drawings are used to as reference over constructions & 0.47 \\
\hline
\end{tabular}

Source: Field data (2019)

From Figure 5 above failure to follow the specification is the source of the end deliverable being not of the clients' expectations. Thus with quality dilemma mean wilks' $\lambda=0.67$ shows most of projects executed by small and medium contracting firms involved in construction of schools, health infrastructures are not confined to the quality standards specified.

Diversion from dimensions specified is the prior source of the project to end while revealed variated from the specifications. Constructions for instance has its specific dimensions such that of length, width, height and thus violations of these parameters equated as mean $\lambda=0.57$.With 
this discrepancy a number of cases has been reported and indeed over the public infrastructures , buildings where while a building had to have a specific feet as height from the foundation it was found to diverge from the specification what entails variations over the deliverables.

The building walls which found to form cracks or faults prior to its construction end is the indicator that less materials were used than the quantity specified or budgeted. The problem was revealed rampat with mean wilks' lambda, $\lambda=0.84$ over a Bill of Quantity ( BoQ). This is the fact in which the same was said by the Minister of Education, Science, and Technology (ITV TV reporter, 2019) that the very weak building wall of which just a slight push fell down was found. This was from Shinyanga region over the completed classrooms which were found weak and non-durable. Moreover the variations were revealed over the drawings (mean wilks' $\lambda=0.47$ and blue prints (mean wilks' $\lambda=0.74$ ) to be not executed. This is the reasons on why most of infrastructures built under force account procurement method are reported not to meet the clients' utility.

\subsection{The level of Managerial Competence in executing Force Account}

Managerial competence implies the extent to which the project runners and managers are able to plan, organize, execute, monitor and evaluate a project. For instance with effective planning the executors of the project stand in a position to identify several types of risks and, areas of exposures and find ways to mitigate them. Un-identified risks are harmful towards performance of the projects (Sunindijo, 2011).More details over the implications of managerial competence towards project performance and the reality over its level of demonstrations has narrated below:-

From Table 2 below for the level of inability to communicate with mean $(\mathrm{X})=4.00<5.00$ and standard deviation $=\delta^{2}=0.77>0.05$ is a proven indicator that the problem persist even to observe the contract or deliverable which was to be completed in determinable time was not so fostered. It is with poor communication or communication breakdown in which the time when materials have finished say with the phase wise project then small and medium contracting firms were revealed to communicate that need until to the very end when materials are coming to zero. This then revealed to be the major cause of the delay of the project to be completed on time.

Delay in completing the contract as it has stipulated above was also revealed to be caused by managerial deficiency of the executors of the contracts. With mean $(X)=4.20<5.00$ and standard deviation $\left(\delta^{2}\right)=0.64>0.05$ is the exactly proof that project delay is costing what local contractors need to mitigate. Infact delay of a project to come to an end is costing to experience the cost of project go beyond to the piled amount and therefore distorting the quality of the output.

More resources or materials use than the budgeted amount has great implication over unoptimum inefficient use of organization resources. More facts and the proof was from the results found from the field as it has shown in the Table 2 above of mean $\left({ }^{-} \mathrm{X}\right)=4.10$ and standard deviations $\left(\delta^{2}\right)=0.52$.It is with more variations observed from the completed projects with mean $(\mathrm{X})=4.70$ and standard deviation $\left(\delta^{2}\right)=0.60$ in which some were also found not durable to deplete in just a moment from its completion time with mean $(\mathrm{X})=3.70$ and standard deviation ( $\left.\delta^{2}\right)=0.45$. 
Furthermore it is a proven fact that for expected deliverable to be achieved then the managerial capability of the contractors is prior requisite to be executed .It is with inability of small and medium enterprises involved in constructions represented by planning deficiency mean $(\mathrm{X})=$ $4.5<5.00$ and standard deviation $\left(\delta^{2}\right)=0.37>0.05$; organization of resources deficiency with mean $(\mathrm{X})=4.60$ and standard deviation $\left(\delta^{2}\right)=0.47$. Moreover the coordination deficiency given the $\mathrm{X}=3.72$ and $\delta^{2}=0.45$; inability to monitor and evaluate the project to its performance with $\mathrm{X}=4.01 / 3.50$ and $\delta^{2}=0.21 / 0.10$ is the indicator that managerial incompetence is part and parcel of operation of most of local contractors. These then are among the reasons why these small and medium contracting firms are not trusted to be given the project to operate (See results in Table 3 below). The facts over most of local contractor to lack experience and managerial competences were also put forward by Amemba et al., (2013) in the study "Challenges Affecting Public Procurement Performance Process in Kenya"

It is with these managerial and technical deficiencies what the Tender Board in procurement framework or Institution has established the structured program called Build and Design (BD) and the TANROADs are also offering BOOT ( Build Operate Own Transfer ) contract.

Table 2: The level Competence demonstrated by local contractors in executing force account

\begin{tabular}{|c|l|c|c|}
\hline S/N & Sub constructs & Mean $(\mathrm{X})$ & Standard deviation $\left(\delta^{2}\right)$ \\
\hline 1 & Inability to communicate & 4.00 & 0.77 \\
2 & Delay in completing the contract & 4.20 & 0.64 \\
3 & More resources use than what was budgeted & 4.10 & 0.52 \\
4 & Completed project found not durable & 3.70 & 0.45 \\
5 & Number of variations revealed over the project & 4.70 & 0.60 \\
& completed & & \\
\hline
\end{tabular}

Source: Field data (2019)

Table 3: Managerial skills and Force account

\begin{tabular}{|c|l|c|c|}
\hline S/N & Sub constructs & Mean $\left({ }^{-X}\right)$ & Standard deviation $\left(\delta^{2}\right)$ \\
\hline 1 & Planning & 4.50 & 0.34 \\
2 & Resources mobilization & 4.60 & 0.47 \\
3 & Coordination & 3.72 & 0.45 \\
4 & Monitoring & 4.01 & 0.21 \\
5 & Controlling & 3.50 & 0.10 \\
\hline
\end{tabular}

Source: Field data (2019)

\subsection{Financial difficulties in implementing Force Account}

One of the requirement for a contractor to win a contract to run is the financial capabilities different from other criteria such that of technical and managerial efficiency. It is because most of small and medium contracting firms are running short of finance that is why executing for force accounts' contracts become difficult. Though by $100 \%$ local contractors, Engineers, 
Architects and Quantity Surveyors are dedicated to operate this force account contracts but only $50 \%$ of this policy is executed. Though there can be other reasons for what is behind the scene but financial difficulties are one among those other factors. The small and medium contractors are not made with structured financial systems. Access to bond or start-up capital is a discrepancy $=45$ (cases 56\%). Banks supporting development of small and medium contracting firms are not accessible adequately by 47 (cases 67.5\%); performance bond/guarantee are not provided for about 69 (cases 54.7\%) and the insurance bonds are not offered by 54 (cases $70 \%$ ).

Figure 5: Financial deficit and execution of Force account Policy

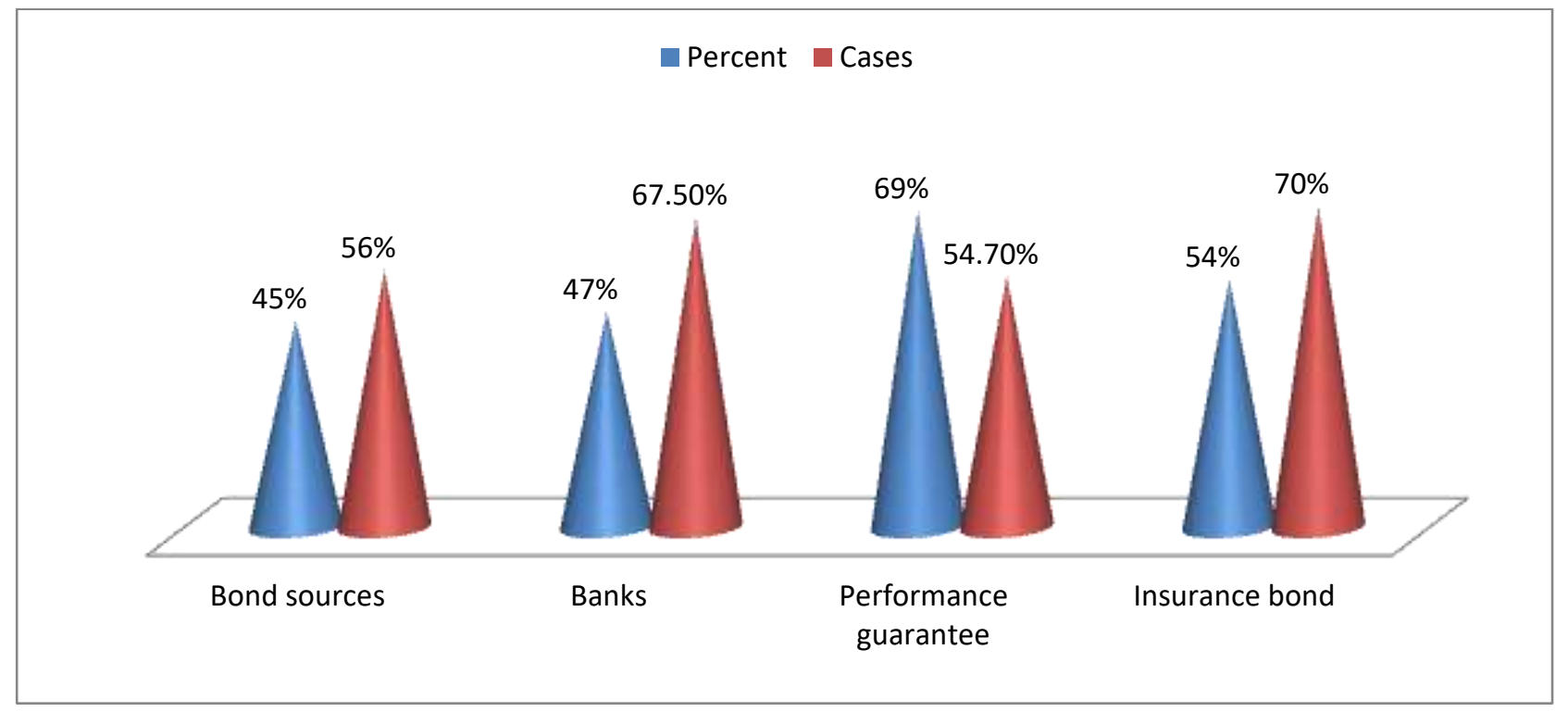

Source: Field data (2019)

\subsection{The level of commitment of Malpractices in executing Force Account}

Demonstration of good governance is one of the criteria the demand side or procuring entity look at when selecting a potential contractor to execute the contract (Huang, 2011). Good governance implies transparency and ethical way of behaving when executing a contract. This is the reason why the responsive bid to be submitted by a bidder need to associate the 'anti-corruption declaration form'. According to Shengeza (2018) transparency is being committed, answerable and accountable for good or bad over the work to be done. Being anti-corrupted, impartial, confidential and keeping secrete are honest behaviors that need to be shown by the contractors in the whole contract management cycle. But with the dishonest malpractices found from the field regarding reported cases 76\% (14) (See Figure 7 below) indicates the extent to which small and medium contracting firms are not honest. This is from the fact that they found to commit defalcation. The materials of constructions sometimes appeared to be misallocated .The dishonest practices were further revealed over the less quantity of materials acquired and being used to than the expected or planned ones. The cases over negligence $=64 \%$ (14) prove the fact 
that for small and medium contracting firms not trusted in their doing is because of demonstrating laziness and non-due care. What was in the minds of local contractors revealed is the careless and profit making but not on the quality of the services provided.

Figure 7: Commitment of Unethical practices

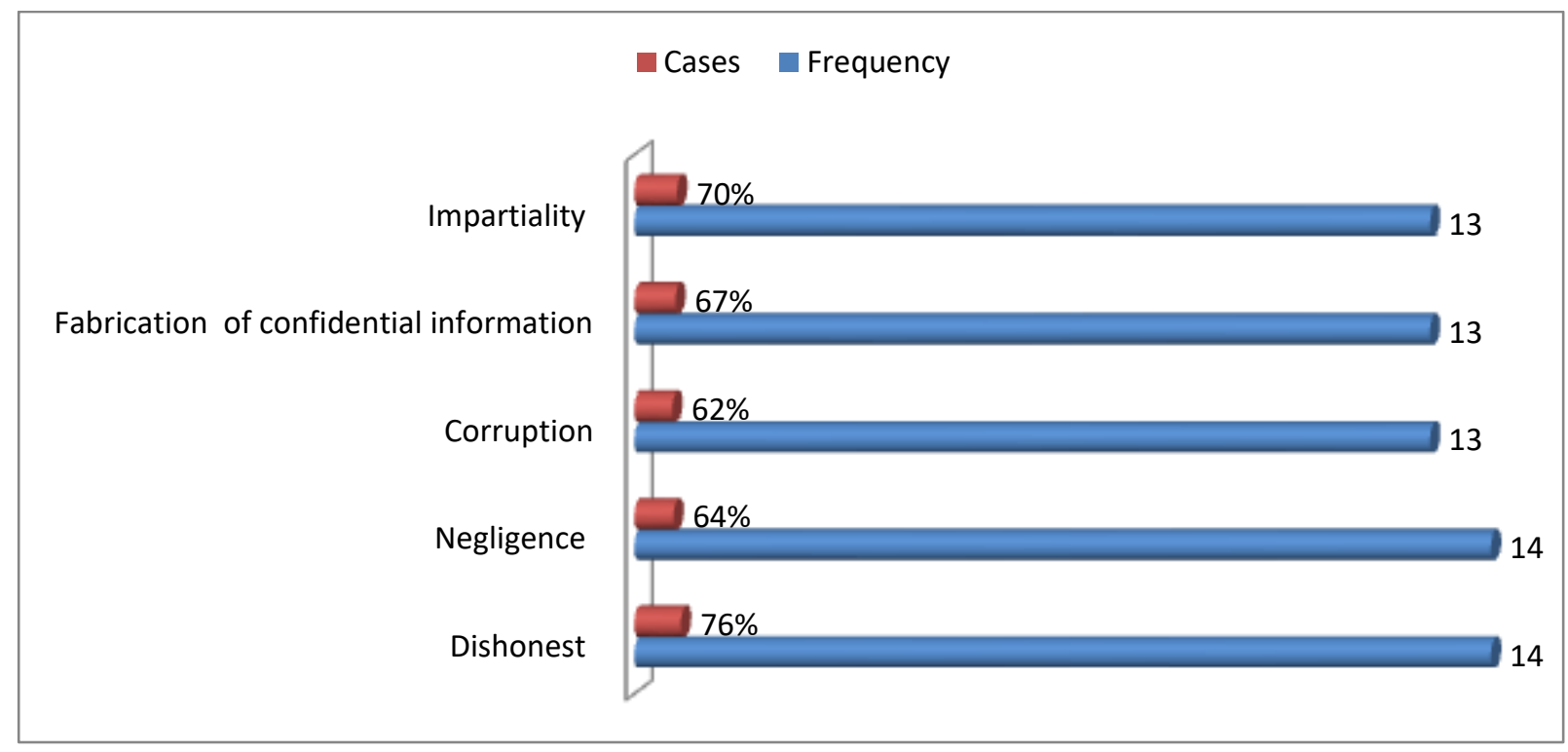

Source: Field data (2019)

Corruption has became a normal business these small and medium contracting firms have been committing .It is with corruption -dishonest practices demonstrated by SM contracting firms what makes the cases report to come to 62\%(13) spreaded (See figure 7 above). While results shown dishonest practices to be part of operations of most of small and medium contracting firms in Tanzania this then run contrarily from what was said Ohashi (2009) on the effects brought by exercising transparency towards getting into Value for Money Procurement in the country of Indonesia. It from the study by Ohashi(2009) in which it was revealed that transparency brought equal chance of winning the contracts advertised by the government of Indonesia thus creating sustainability to procurement undertakings. In Tanzania and indeed to the research area the situation found to be bad to observe the materials and equipments acquired for construction purpose were delivered less than the specified quantity and contrarily from the Value of Money allocated for. In some municipals of Mbeya region school construction materials that cost large was different from the quantity of those materials delivered. With reference to the investigative Auditing conducted in one of the public health centre in Mbalizi municipal it was revealed that the cost of materials incurred (as indicated from Purchase Requisition form) was different from the cost sacrificed for and different from the quantity delivered.

Fabrication of unauthorized information was one of the indicator that dishonest practices are committed $=67 \%$ cases $(13)$. This therefore a sign that confidentiality and impartiality way doing 
was not part of most of small and medium enterprises .This unethical practice was clearly defined or demonstrated and reported by one of the technician from REA agency that electrical installation project which was to be in-acted in a particular village with a specified bill of Quantities was not done but non-specifications committed and the project being shifted to another village which was not in the recent plan. Non-impartiality moreover go together with preferential treatment showed by procuring agents from TARURA to have a preference to particular experts who observed or found to be hired now and then in construction of public infrastructures.

\subsection{Regresiveness of tax charged on small and medium contracting firms}

Unfair tax system, being regressive in nature say the VAT paid without regarding the youngness of the contracting firm and most of them being paid by referring to the income received and not on profit revealed. The hurt tax $(74 \%)$ charged on capital inputs discourage investments being a reason why most of small and medium enterprises are not able to start and run business on their own. It is from the same point why other authors are suggesting on SMEs to be capacitated financially and if that is not enough then Banks for Contractors, Engineers and Architects should be established in Tanzania. Unfair VAT $18 \%$ equated to $69 \%$ and corporate tax for established SME of about $30 \%$ equated to $65 \%$ (See Figure 8 below) being responses gathered from the field is the proven facts of what was said by one of small contractor that his business has been operating informally while unregistered, non-licensed and non-insured. This was so because of these firms trying to avoid tax from its regressive pinching effect.

\section{Figure 8: The level of unfairness of tax charged}

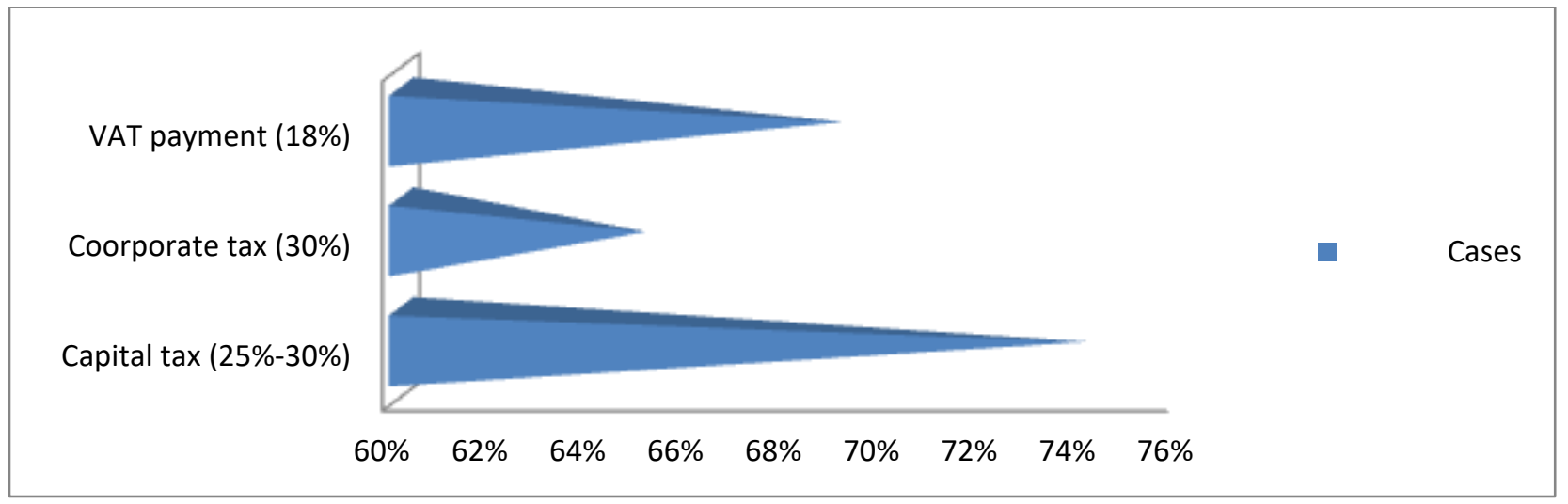

Source: Field data (2019)

The results over dominance of local contracting firms in Tanzania as shown above in figure 8 to be caused by tax rate to be not fair are consistent with what was reported by Shi-Xueyong (2009) thought the research areas differentiate these two studies in which while that of Shi-Xueyong (2009) was conducted in Dar Es Salaam this study under discussion was carried out in Mbeya. 


\section{CONCLUSION}

Force account for development of small and medium contracting firms came out after the reforms in procurement of PPA 2004 to PPA 2011. Force account policy aim for good but due to stiff challenges facing the local contractors that is why it is little $<60 \%$ of the value executed. Moreover despite of the good motive of developing SMEs indeed in construction industry by empowering them technically, financially, managerially competence but from the field it was revealed that little was demonstrated. It was found that insignificant development is because of the i) financial difficulties ii) managerial incompetence and non-experience over the work to be executed iii) malpractices and more other dishonest practices as well as v) tax burden.

To be attained to full exhaustment of force account then the followings are to be taken for action:-

i) Local contractors have to form joint tenancy that will empower them financially, gain image and trust to be awarded many projects as possible for those ones under force account and those executed under National competitive tendering and International competitive tendering procurement methods.

ii) Through collaboration then the SMEs are to form SACCOS for them to be empowered financially and gain trust by financial Institutions for them to be learnt money.

iii) Promotion of structural training programs to be facilitated by National Construction Council (NCC).

iv) Emphasize is to be put for local contractors to be registered in the professional Boards i.e. the CRB, ERB, AQRB

v) Use of BOOT i.e. Build Operate Own Transfer

vi) Use of Tax breakage or incentives to promote development of SME

vii) Reminding contractors on the importance of acting honestly and observing code of conducts

viii) Formalization of the firms operated by small and medium contracting firms

\section{References}

Amemba, C. S., Nyaboke, P. G., Osoro, A., \& Mburu, N. (2013). Challenges Affecting Public Procurement Performance Process in Kenya. International Journal of Research in Management, 3(4): 41-55.

BMAU (2015).Using Force Account for Road Maintenance: Were Local Governments Ready?(Briefing Paper). Kampala, Uganda. [Online]. Available at http://mambosms.ug/Data/atha/finance/dmdocuments/BMAU\%20Briefing\%20Paper\%2 017\%20\%20Using\%20Roce\%20Account $\% 20$ for\%20road\%20maintenance $\% 20 \% 20 \mathrm{We}$ re\%20Local\%20Governments\%20ready.pdf. 
Dlungwana, W.S. \& Rwelamila,K. (2018 ).Division of Building and Construction Technology, CSIR, PO Box 395, Pretoria, 0001, South Africa. sdlungwana@csir.co.za P.D.

Enshassi, 1. \& El Karriri (2011).Contractors Bidding Behaviors in Palestinian Construction Industry. Unpublished Master's Dissertation, the Islamic University, Palestine.

Hernes, T. (1988).Training Contractors for Result: A Guide for Trainers and Training Managers, International Labour Organization.

Huang, X. (2011).An Analysis of the Selection of Project Contractor in the Construction Management Process (www). International Journal of Business and Management, 6,(3). Retrieved on 28/1/2012 from World Wide Web: www.ccsenet.org/ijbm.

ITV TV Reporter (2019). Durability of projects executed by Local Contractors defined under force account. Shinyanga-Tanzania on $23^{\text {rd }}$ June 2019.

Kajwangya, D. (2008).Identification of Areas where Improvement is needed in Order to Promote Local Bidders in Responsive Tender; the Experience of Public 84 Procurement in Tanzania, Unpublished Master's Dissertation, Mzumbe University.

Kaula, S.(2017). Why most of procurement opportunities in Tanzania are won by foreign contractors?. Mbeya-Tanzania: Unpublished research paper.

Nasser, S. A. (2011). Improving Bidders Competitiveness Strategies in construction industry Projects - Gaza Strip. Unpublished Master's Dissertation, the Islamic University, Palestine.

Ofori, G.(2000). Department of Building, National University of Singapore 4 Architecture Drive, SINGAPORE 117566.

Ohashi, H.(2009).Effects of Transparency in Procurement Practices on Government Expenditure: A Case Study of Municipal Public Works." Review of Industrial Organization, 34(3): 267-285.

Public Procurement Act, No. 21 of 2011 and it Regulations, Public Procurement (Goods, nonconsultant services. disposal of public Assets by Tender) Regulations, 2005, GN.97 of 2013.

Schapper, P. R., Veiga Malta, J. N., \& Gilbert, D. L. (2006). An Analytical Framework for the Management and Reform of Public Procurement. Journal of Public Procurement, 6(1\&2): 1-26.

Shengeza,J. (2018).Procedure on Effective Application of Force Account as a Method of Procurement for Renovation and Remodeling of Government Building Projects, Journal of Civil, Construction and Environmental Engineering, vol. 2, no. 6, pp. pp 153-158.

Shi-Xueyong, S.(2009). A tentative Analysis of Challenges and Correspondent Strategies for Small \& Medium Sized Contractors in Tanzania. The Contractor, (3), pp. 36-37. 
Sunindijo, R.Y. (2011). Essential skills for construction project managers. International Journal of Project Organization and Management 3(2):139 - 163 - January 2011. Tender registers, TARURA HQ.

Uganda National Association Of Building and Civil Engineering Contractors, (UNABCEC) ( 2014). Strategies for developing local contractors in Uganda.

Valdovinos, V.P.E. \& Lorick, H. C.(2013).Getting Maintenance Work Done: In-House or by Others." (Water Online). [Online]. Available at https://www.wateronline.com/doc/gettingmaintenance-work-done-in-house-or-byothers-0001 (Accessed: 02.05.2018).

\section{Copyrights}

Copyright for this article is retained by the author(s), with first publication rights granted to the journal.

This is an open-access article distributed under the terms and conditions of the Creative Commons Attribution license (http://creativecommons.org/licenses/by/4.0/) 